\title{
Electrodeposition of Nanometer-Sized Ferric Oxide Materials in Colloidal Templates for Conversion of Light to Chemical Energy
}

\author{
James M. Gardner, Su Kim, Peter C. Searson, and Gerald J. Meyer \\ Departments of Chemistry and Materials Science and Engineering, Johns Hopkins University, \\ 3400 North Charles Street, Baltimore, MD 21218, USA \\ Correspondence should be addressed to Gerald J. Meyer, meyer@jhu.edu
}

Received 2 June 2010; Accepted 23 July 2010

Academic Editor: William W. Yu

Copyright ( 92011 James M. Gardner et al. This is an open access article distributed under the Creative Commons Attribution License, which permits unrestricted use, distribution, and reproduction in any medium, provided the original work is properly cited.

Colloidal crystal templates were prepared by gravitational sedimentation of 0.5 micron polystyrene particles onto fluorine-doped tin oxide (FTO) electrodes. Scanning electron microscopy (SEM) shows that the particles were close packed and examination of successive layers indicated a predominantly face-centered-cubic (fcc) crystal structure where the direction normal to the substrate surface corresponds to the (111) direction. Oxidation of aqueous ferrous solutions resulted in the electrodeposition of ferric oxide into the templates. Removal of the colloidal templates yielded ordered macroporous electrodes (OMEs) that were the inverse structure of the colloidal templates. Current integration during electrodeposition and cross-sectional SEM images revealed that the OMEs were about $2 \mu \mathrm{m}$ thick. Comparative X-ray diffraction and infrared studies of the OMEs did not match a known phase of ferric oxide but suggested a mixture of goethite and hematite. The spectroscopic properties of the OMEs were insensitive to heat treatments at $300^{\circ} \mathrm{C}$. The OMEs were utilized for photoassisted electrochemical oxidation. A sustained photocurrent was observed from visible light in aqueous photoelectrochemical cells. Analysis of photocurrent action spectra revealed an indirect band gap of $1.85 \mathrm{eV}$. Addition of formate to the aqueous electrolytes resulted in an approximate doubling of the photocurrent.

\section{Introduction}

There is an urgent need to find inexpensive and sustainable inorganic materials for converting solar photons into chemical energy. Splitting water with metal oxides and sunlight is a very appealing idea that has caught the attention of scientists for decades [1]. One approach has been to utilize a metal oxide photoelectrode that can photo-oxidize water and provide electrons to a platinum electrode for proton reduction [2]. Shown in Figure 1 is a simplified version of such a cell. To aid in hydrogen gas collection and to prevent $\mathrm{O}_{2}$ reduction at the platinum electrode the two electrodes can be separated by a salt bridge or porous membrane.

Fujishima and Honda first reported sustained water splitting through this approach with $\mathrm{TiO}_{2}$ [2]. Unfortunately, the unfavorable band gap of rutile $\mathrm{TiO}_{2}(3.1 \mathrm{eV})$ resulted in a very low solar conversion efficiency $(<1 \%)$. Later, other wide band gap metal oxides were shown to work in a similar fashion [3-5]. Hematite, $\alpha-\mathrm{Fe}_{2} \mathrm{O}_{3}$, has a much more favorable $2.2 \mathrm{eV}$ band gap for solar harvesting and therefore absorbs about $40 \%$ of the air mass 1.5 solar spectrum [68]. Previous researchers found that the energetic position of the valence band edge in hematite is appropriate for water oxidation [9-21]. In fact, iron oxides are amongst the smallest band gap semiconductors that are stable toward oxygen evolution and are certainly the least expensive of them. However, overall charge collection efficiencies from hematite in photoelectrochemical cells has been disappointingly low [6].

Much of the early work on hematite photoelectrochemistry was done in the 1970-1980s; however, recently there have been a few promising reports [22-34]. Poor solar charge collection efficiency was attributed to low minority (hole) diffusion lengths [30]. In other words, photogenerated valence band holes do not efficiently reach the hematitewater interface and primarily recombine in the bulk. In 


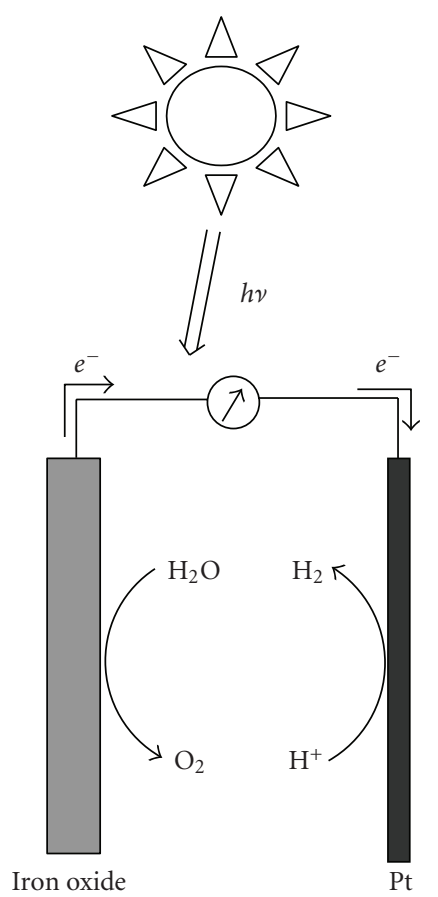

Figure 1: Photoelectrosynthetic cell for splitting water into $\mathrm{H}_{2}$ and $\mathrm{O}_{2}$. The two electrodes can be separated by a physical barrier to aid in gas collection.

principle, this problem can be circumvented with iron oxide electrodes that have architectures tailored towards high surface area and minimal internal volume such that all photogenerated holes reach the solution interface.

New processing techniques that have been developed in the last twenty years may enable the production of semiconductor materials with architectures ideal for charge capture at a solution interface. Colloidal templates offer interesting possibilities in this regard as they could allow ferric oxide structures to be controlled with considerable precision $[35,36]$. The average distance photogenerated holes would need to travel to reach the interface can be systematically tuned by varying the size of the colloidal particles used in the template. High surface area, porous materials that can be fine tuned to optimize hole capture at the aqueous interface are expected to be ideal for light harvesting and oxygen evolution in photoelectrosynthetic cells. Furthermore, hole transfer and/or oxidation catalysts, such as $\mathrm{RuO}_{2}$ and $\mathrm{IrO}_{2}$ could be included at desired locations within the structure to decrease oxidation overpotentials and improve kinetics [1]. Recently we have initiated experiments to establish whether colloidal templates could be used to fabricate ferric oxide in ordered macroporous thin films. Here we report that this can indeed be accomplished and report the synthesis of ordered ferric oxide electrodes. Photoelectrochemical studies with the templated ferric oxide materials reveal small sustained photocurrents that may be consistent with water oxidation, but the present architecture is not suitable for practical application in photoassisted water oxidation.

\section{Experimental}

2.1. Materials. $\mathrm{FeCl}_{2} \cdot 4 \mathrm{H}_{2} \mathrm{O}$ (Aldrich, $99 \%$ ), L-ascorbic acid (Aldrich, >99\%), NaCl (Mallinckrodt Chemicals, >99.0\%), 1-methylimidazole (Aldrich, 99\%), polystyrene (PS) microbeads (Polysciences, $0.5 \mu \mathrm{m}$ diameter), ethanol (Aaper Alcohol, anhydrous 200 Proof), $\mathrm{NaOH}$ (Fisher, 97.5\%), $\mathrm{NaCHOO}$ (Aldrich, 99+\%), and $\mathrm{Na}_{2} \mathrm{SO}_{4}$ (EMD, 99.0+\%) were used without further purification. Electrolytes for electrodepositions used HPLC grade water; all other solutions used deionized water. Conductive fluorine doped tin oxide glass, FTO (Hartford Glass, $\mathrm{SnO}_{2}: \mathrm{F}$ ) and Au evaporated $\mathrm{Si}$ wafers were cleaned with water and ethanol prior to electrodeposition.

2.2. Templating. The assembly of the colloidal crystalline template followed literature preparations, described briefly as follows [37, 38]. Sheets of FTO or wafers of gold evaporated on silicon were cut to $4.0 \mathrm{~cm} \times 2.5 \mathrm{~cm}$ dimensions and uses as substrates. They were first sonicated in glass vials with absolute ethanol, rinsed with deionized water, and dried under compressed air. Viton and Teflon o-rings were also rinsed with deionized water and dried under compressed air. The Viton o-ring was placed on the conductive side of the substrate. The Teflon o-ring was placed on top of the Viton o-ring. Both rings were clamped onto the substrate using binder clips. The PS particles were diluted by $1: 8$ $\mathrm{v}: \mathrm{v}$ in deionized water and stored at $4^{\circ} \mathrm{C}$. Prior to assembly the suspension was sonicated for two minutes. A $170 \mu \mathrm{L}$ aliquot of the diluted PS particle suspension was carefully pipetted onto the substrate and was placed in a humidity chamber at room temperature and $85 \%$ humidity. After six days the clamps and o-rings were removed leaving an ordered colloidal crystal template. The substrate was cut to the width of the template yielding a templated electrode $1.0 \mathrm{~cm} \times 4.0 \mathrm{~cm}$, which was stored in a humidity chamber until use.

2.3. Electrodeposition. Ferric oxide was electrodeposited into the colloidal crystalline templates. Electrodeposition was carried out in an Ar purged, septa sealed, three electrode cell with the colloidal crystal template as the working electrode, FTO as the counter electrode, and $\mathrm{Ag} / \mathrm{AgCl}$ $(\mathrm{KCl}$ saturated) as a reference electrode. All potentials are reported with respect to the $\mathrm{Ag} / \mathrm{AgCl}$ reference $\left(U_{\mathrm{eq}}=\right.$ $+0.110 \mathrm{VSHE}$ ). The electrodeposition solution contained $50 \mu \mathrm{L}$ of $1 \mathrm{M} \mathrm{FeCl}_{2}$ solution, $150 \mu \mathrm{g}$ of $\mathrm{L}$-ascorbic acid, and $5 \mathrm{~mL}$ of a $0.4 \mathrm{M} \mathrm{NaCl}$ and $0.1 \mathrm{M} \mathrm{1-methylimidazole}$ electrolytic solution [39]. Ferric oxide was deposited at $-0.30 \mathrm{~V}$ under a slow purge of nitrogen in the head space until $-0.30 \mathrm{C} / \mathrm{cm}^{2}$ were passed. The film was then immersed in toluene for ten minutes. The electrodeposited ferric oxide adhered to the FTO as an ordered macroporous electrode (OME). The OME were removed from the toluene and stored in sealed glass vials until use. Preparation of the template and electrodeposition onto $\mathrm{Au}$ evaporated $\mathrm{Si}$ wafers followed the same methods used for OMEs on FTO. 
2.4. Characterization. Environmental scanning electron microscope (ESEM) images were taken on an FEI Quanta 200 Environmental SEM at a water vapor pressure of $1.8 \mathrm{kPa}$. Cross sectional SEM images of colloidal crystalline templates and ferric oxide OME deposited on Au that had been evaporated onto Si wafers were acquired with a JEOL $6700 \mathrm{~F}$ Scanning Electron Microscope. The UV/Visible electronic spectra were acquired on a Cary 500. Fourier transform infrared (FTIR) spectra were acquired on a Thermo Nicolet Nexus 670 FTIR with a Smart Golden Gate ATR attachment. X-ray diffractograms (XRD) were acquired on a Philips X'Pert Pro X-ray Diffraction System using $\mathrm{Cu}-\mathrm{K} \alpha$ radiation. For XRD measurements, the ferric oxide OME was removed from the FTO substrate with a razor blade. All other characterization techniques were acquired on intact ferric oxide OME.

2.5. Photoelectrochemistry. Photocurrent action spectra were recorded with a Keithley 5000 electrometer under short circuit conditions in a custom-built liquid junction Teflon cell with a Pt mesh counter electrode. The electrolyte was $0.1 \mathrm{M} \mathrm{NaCl}$ at $\mathrm{pH} 9.5$ adjusted with $\mathrm{NaOH}$. The light source was a $100 \mathrm{~W}$ Xe arc lamp (Spectra Physics) attached to a monochromator (Oriel Instruments Corner Stone $1 / 4 \mathrm{~m}$ ). Incident irradiances were measured with a UDT high sensitivity silicon diode optometer.

Photocurrents were also measured in a three-electrode arrangement with a BAS CV50-W potentiostat. The working electrode was a ferric oxide OME with a $\mathrm{Pt}$ mesh counter electrode and a $\mathrm{Ag} / \mathrm{AgCl}$ reference electrode. The aqueous electrolytes used were either $0.5 \mathrm{M} \mathrm{Na}_{2} \mathrm{SO}_{4}$ or $0.1 \mathrm{M} \mathrm{NaCHOO} / 0.5 \mathrm{M} \mathrm{Na}_{2} \mathrm{SO}_{4}$. In a typical experiment, the applied bias was ramped from $0.0 \mathrm{~V}$ to $+1.3 \mathrm{~V}$ at a scan rate of $2 \mathrm{mV} / \mathrm{s}$. This was then repeated with the ferric oxide OME illuminated with $20 \pm 1 \mathrm{~mW} / \mathrm{cm}^{2}$ of $413.1 \mathrm{~nm}$ light from a Continuum $\mathrm{Kr}$ ion laser. The photocurrents are reported as the total current measured under illumination minus the dark current.

\section{Results}

The colloidal crystal templates were prepared by gravitational sedimentation of polystyrene (PS) particles onto fluorine-doped tin oxide (FTO) electrodes. The quality of the crystal was dependent on the particle concentration, temperature, and relative humidity. The conditions used ensured controlled evaporation of the solvent and sufficiently slow sedimentation to result in well-ordered crystals. Faster evaporation rates typically resulted in defects such as cracks or voids that led to large volumes of solid in the replica after deposition. Figure 2 shows SEM images of a typical $4 \mu \mathrm{m}$ thick colloidal crystal template formed by this technique. The image shows that the particles were close packed, and examination of successive layers confirmed a predominantly face-centered-cubic (fcc) crystal structure where the direction normal to the substrate surface corresponds to the (111) direction.

Ordered macroporous electrodes (OMEs) of ferric oxide were formed by electrodeposition into the templates at
$-0.30 \mathrm{~V}(\mathrm{Ag} / \mathrm{AgCl})$. The deposition charge of $0.30 \mathrm{C} / \mathrm{cm}^{2}$ corresponded to an OME thickness of $2 \mu \mathrm{m}$, in reasonably good agreement with values obtained from cross-sectional SEM images $(2.8 \pm 0.1 \mu \mathrm{m})$. The PS particles were removed by immersion in toluene that left an orange-red OME on the FTO substrate.

A representative plan view SEM image of a ferric oxide OME is shown in Figure 3(a). The top surface revealed a close packed mesostructure that was a replica of the colloidal crystal template. The domain size was $15-50 \mu \mathrm{m}$ and the OMEs were free from cracks or voids. The surface roughness factor, or rugosity, of a $2.8 \mu \mathrm{m}$ thick OME was about 25 corresponding to about 6.5 layers of template as seen in the cross-sectional SEM, Figure 3(b).

Attenuated total reflection Fourier transform infrared, ATR-FTIR, spectroscopic characterization of the OMEs were performed, Figure 4. The broad $\mathrm{O}-\mathrm{H}$ stretch at $3200 \mathrm{~cm}^{-1}$ and overtone at $1600 \mathrm{~cm}^{-1}$ are diagnostic of adsorbed water [41]. The intensity of these bands decreased after heating the $\mathrm{OME}$ at $300^{\circ} \mathrm{C}$ for 30 minutes. The heat treatment did not significantly change the FTIR spectra of other regions of the spectra.

X-ray diffraction (XRD) analysis of the electrodeposited ferric oxide showed weak intensity and broad angular distribution of the diffraction peaks, Figure 5. Superimposed on this data are the literature values for the diffraction peaks of goethite and hematite $[40,42]$.

Shown in Figure 6(a) is the transmittance spectrum of a ferric oxide OME. The transmittance is near zero in the ultraviolet region and increased to near unity in the near-IR region. At longer wavelengths some of the transmission loss can be attributed to light scattering by the film.

The photocurrent efficiency of the ferric oxide OMEs was evaluated in two- and three-electrode arrangements in aqueous electrolytes at $\mathrm{pH}$ 9.5. The incident photon-tocurrent efficiencies (IPCEs) were calculated with

$$
\operatorname{IPCE}=\frac{[1240 \mathrm{eV} \mathrm{nm}]\left[\text { photocurrent density }\left(\mu \mathrm{Acm}^{-2}\right)\right]}{[\text { wavelength }(\mathrm{nm})]\left[\text { irradiance }\left(\mathrm{mW} \mathrm{cm}^{-2}\right)\right]} \text {. }
$$

Here the photocurrents were measured on OMEs of known area with a potentiostat or an electrometer. The irradiance was quantified with a calibrated silicon photodiode in the same arrangement.

Shown in Figure 6(a) is the IPCE recorded as a function of the excitation wavelength, a photocurrent action spectrum, measured under short circuit conditions. The maximum observed IPCE was $0.7 \pm 0.1 \%$ at $370 \mathrm{~nm}$. This value is likely an underestimation of the true photocurrent yield, because no corrections were made for light absorption and scattering by the FTO substrate. The IPCE tailed into the visible region with no measurable photocurrent response at wavelengths longer than $600 \mathrm{~nm}$.

The gradual increase in the photocurrent magnitude with increasing photon energy is typical of indirect semiconductors. For an indirect band gap semiconductor:

$$
\mathrm{IPCE} \cdot h v=A\left(h v-E_{g}\right)^{2}
$$




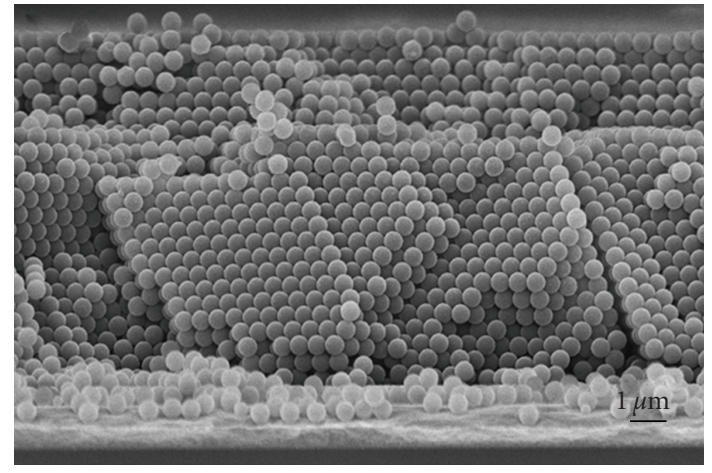

(a)

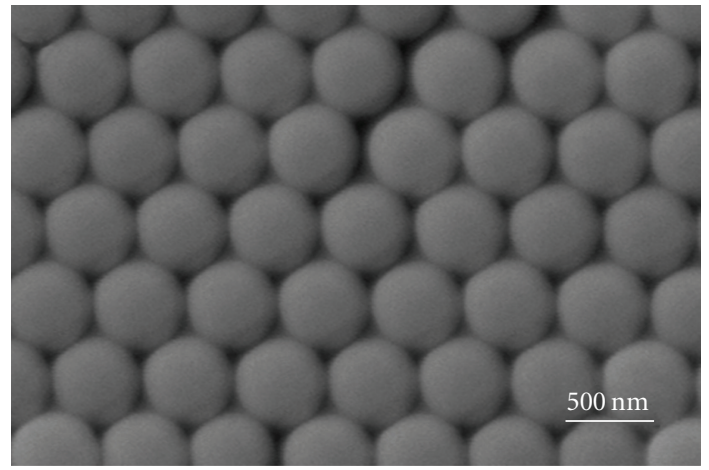

(b)

Figure 2: (a) Cross section and (b) plan view SEM image of a colloidal crystal template formed from 500 nm polystyrene (PS) particles.

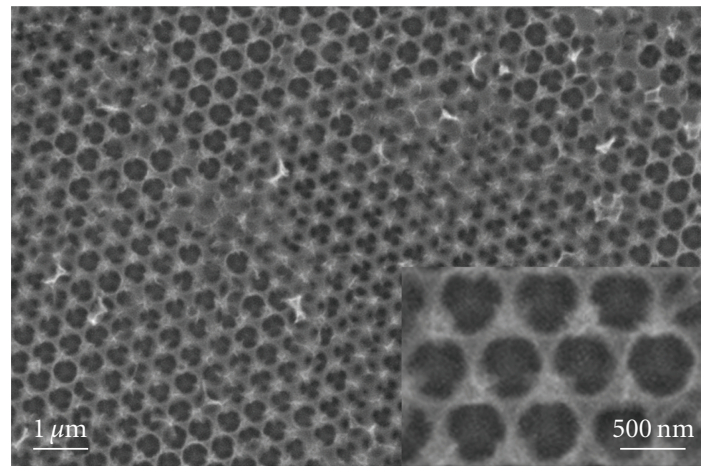

(a)

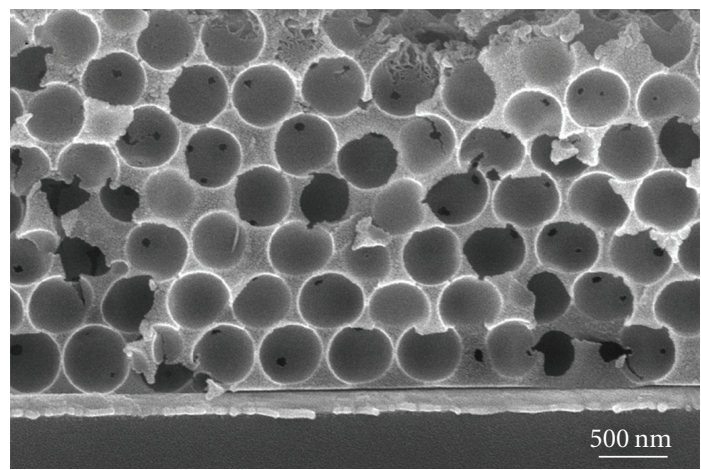

(b)

FIgure 3: (a) A plan view ESEM image of an electrodeposited ferric oxide OME surface fabricated by deposition into a colloidal crystal assembled from $0.5 \mu \mathrm{m}$ diameter polystyrene particles. Inset: OME at higher magnification. (b) An SEM image of a cross section of a ferric oxide OME.

where $h \nu$ is the excitation energy, $A$ is a constant, and $E_{g}$ is the band gap $[3,43]$. Figure $6(\mathrm{~b})$ shows a plot of $[\mathrm{IPCE} \cdot h \nu]^{1 / 2}$ versus $h v$ illustrating linear behavior over a wide range of photon energies. The band gap was obtained from extrapolation of the linear region. For a large number of samples the band gap was determined to be $E_{g}=1.85 \pm$ $0.05 \mathrm{eV}$.

Shown in Figure 7 are current-voltage curves for the OMEs in the dark and under illumination. Data are shown in the presence and absence of formate ion. The difference between the current collected in the dark and under illumination was the photocurrent. The photocurrents in the presence and absence of formate were converted to IPCEs to correct for differences in electrode area and light intensity. The observed IPCE was nearly twice as large in the presence of formate as in its absence for all potentials where measurable photocurrents were observed.

\section{Discussion}

The electrodeposition of ferric oxides into colloidal crystal templates has been successfully achieved for the first time.
Removal of the colloidal templates resulted in ordered macroporous electrodes (OMEs) that were utilized for photoassisted electrochemical oxidation. Our results suggest a possible new direction toward the realization of efficient charge capture from excitation of iron oxides with solar photons.

Environmental scanning electron microscopy revealed ferric oxide OME materials with architectures that would be expected based on the inverse structure of the colloidal templates. Infrared studies and X-ray diffraction data did not clearly match a known phase of ferric oxide [39, $40,42]$. The diffraction pattern showed peaks that were consistent with the major diffraction lines for a mixture of goethite and hematite, which represent the two most common polymorphs of ferric oxide [40,44]. Very minor spectroscopic changes were observed after heat treatments at $300^{\circ} \mathrm{C}$, conditions where crystalline ferric oxides, such as $\alpha$ - $\mathrm{FeO}(\mathrm{OH}), \beta-\mathrm{FeO}(\mathrm{OH})$, and $\gamma-\mathrm{FeO}(\mathrm{OH})$, and ferrihydrite, are known to be converted to the more thermodynamically stable hematite [40]. The stability of the ferric oxide OMEs to elevated temperature is surprising and could be exploited for additional processing steps such as the deposition of oxygen evolution catalysts. 


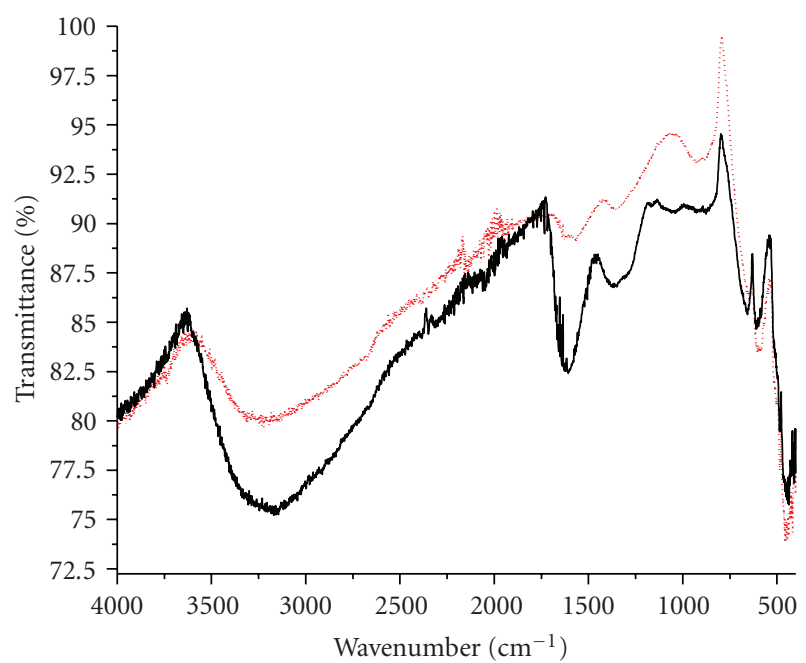

FIGURE 4: ATR-FTIR spectra of an electrodeposited ferric oxide OME like that in Figure 2 before (solid) and after (dotted) annealing at $300^{\circ} \mathrm{C}$.

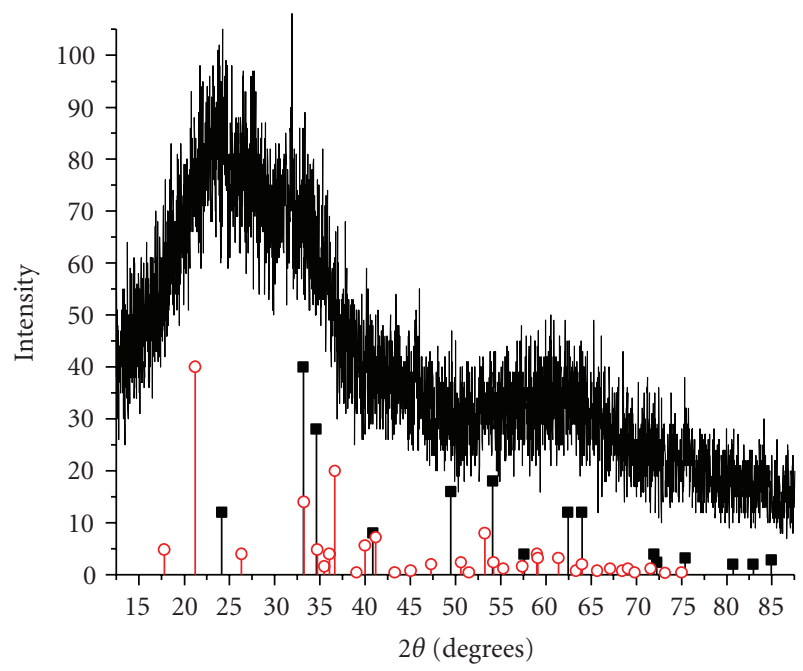

Figure 5: X-ray diffraction pattern of an electrodeposited ferric oxide OME. Also shown for comparison are the peaks for goethite (open circles) and hematite (closed squares) crystals using $\mathrm{Cu}-\mathrm{K} \alpha$ radiation [40].

When utilized in alkaline aqueous photoelectrochemical cells the ferric oxide OMEs yielded a small sustained photocurrent. The direction of the current was consistent with an oxidation reaction at the illuminated OME and n-type behavior [8]. Under short-circuit conditions the maximum incident photon-to-current (IPCE) efficiency was $0.7 \pm 0.1 \%$. Due to low photocurrent densities, no attempts were made to quantify if the photocurrent was from the formation of oxygen. Photocurrent action spectra revealed a maximum at about $370 \mathrm{~nm}$ that tailed into the visible region. A photocurrent was measured with green light and wavelengths $>500 \mathrm{~nm}$. Analysis of the photocurrent action spectra revealed an indirect band gap of $1.85 \mathrm{eV}$. This is significantly smaller than that measured for other

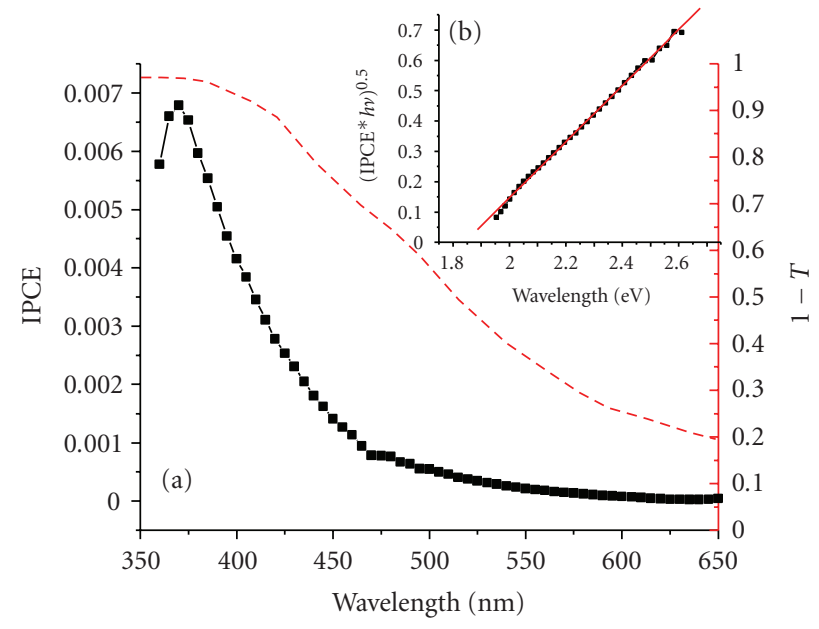

FIGURE 6: (a) A comparison of the short circuit incident photon-tocurrent efficiency (IPCE, squares) of a ferric oxide OME in $0.1 \mathrm{M}$ $\mathrm{NaCl}$ at $\mathrm{pH}$ 9.5. Also shown is the transmittance spectrum (1-T, dashes) of the same material in air. (b) Band gap analysis of the IPCE.

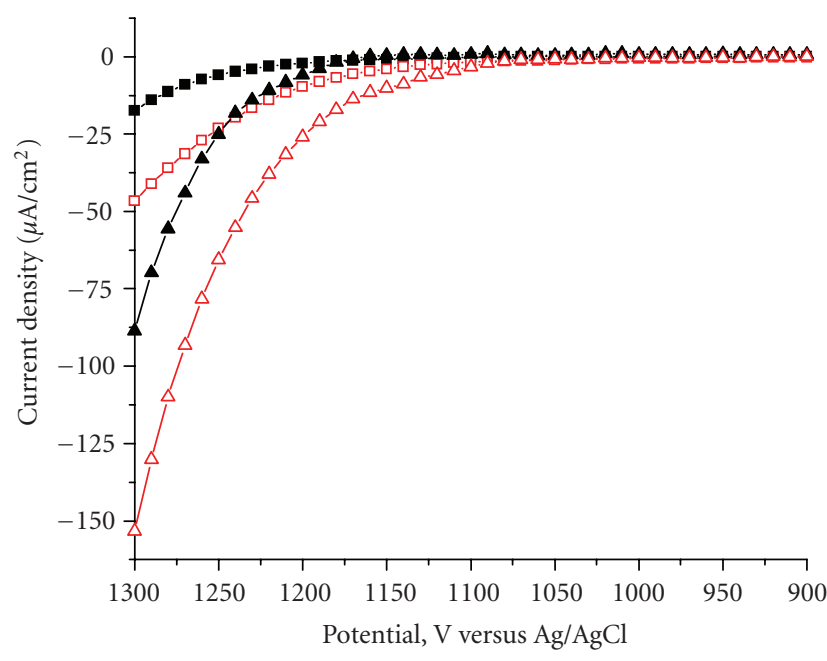

FIGURE 7: Current-voltage curves of electrodeposited ferric oxide OMEs in $0.5 \mathrm{M} \mathrm{Na}_{2} \mathrm{SO}_{4}$ (squares) and $0.5 \mathrm{M} \mathrm{Na}_{2} \mathrm{SO}_{4}$ with $0.1 \mathrm{M}$ $\mathrm{NaCHOO}$ (triangles). The data were measured in the dark (closed) and under illumination (open) with $20 \mathrm{~mW} / \mathrm{cm}^{2}$ of $413 \mathrm{~nm}$ light excitation.

ferric oxides, Table 1 , and is nearly ideal for water splitting applications [40,44]. The comparatively small band gap allows for more efficient solar photon harvesting by the OME than by other ferric oxide phases.

In a 3-electrode photoelectrochemical cell, a gradual increase in the photocurrent was observed as the applied potential was increased. The addition of formate to the electrolyte resulted in an approximate doubling of the magnitude of the photocurrent. It is known that the one electron oxidation of formate produces a highly energetic radical that can inject electrons into the conduction band of some semiconductors, effectively doubling the current $[45,46]$. Kennedy and Frese have previously suggested that 
TABle 1: Band Gaps of Common Ferric Oxides.

\begin{tabular}{lcc}
\hline Ferric Oxide & $E_{g}(\mathrm{eV})$ & References \\
\hline Hematite & 2.20 & {$[40,44]$} \\
Goethite & 2.10 & {$[40,44]$} \\
Akaganeite & 2.12 & {$[40,44]$} \\
Lepidocrocite & 2.06 & {$[40,44]$} \\
Ferric Oxide OME & 1.85 & here \\
\hline
\end{tabular}

current doubling occurs at illuminated hematite electrodes [15] and these results indicate that it also present with ferric oxide OMEs. At potentials greater than $+1.2 \mathrm{~V}$ versus $\mathrm{Ag} / \mathrm{AgCl}$ a dark oxidation current increased dramatically so that such positive excursions were avoided.

Small photocurrents observed at hematite single crystal and thin film electrodes have previously been attributed to short minority carrier (hole) diffusion lengths [6]. In previous work, ordered arrays of hematite nanorods were employed to minimize the distance holes that travel to reach the aqueous interface. Indeed, an increased photocurrent efficiency was observed $[30,47]$. In principle, a benefit of ordered nanorod arrays over the OMEs studies here is the direct path for electron transport to the current collector that minimizes transit time by reducing lateral electron transport. On the other hand, high aspect ratio nanorod or nanowire arrays tend to be fragile with no lateral connectivity to provide the structural support present in the interconnected porous architecture of OMEs.

The largest solid features in the ferric oxide OME reported here come from the tetrahedral and octahedral sites in the colloidal crystal template [38]. The tetrahedral sites are formed from four spheres where the centers of the spheres form a tetrahedron. Equivalently, the tetrahedral site results from a sphere that occupies a threefold hollow site on a close packed plane. The octahedral sites are formed from six spheres and correspond to the unoccupied threefold hollow sites in the close-packed planes. For the OMEs fabricated here with $500 \mathrm{~nm}$ particles as templates, the diameters of the large solid regions, corresponding to the largest spheres that can fit into the tetrahedral and octahedral sites. These are $113 \mathrm{~nm}$ and $207 \mathrm{~nm}$, respectively [38]. Thus the longest distances for carrier diffusion in these structures are $57 \mathrm{~nm}$ and $104 \mathrm{~nm}$. Kennedy and Frese reported hole diffusion lengths of 2-4 $\mathrm{nm}$ [15], while DareEdwards et al. found them to be somewhat larger, $20 \mathrm{~nm}$ [9]. This photoelectrochemical data is consistent, at least qualitatively, with the short lifetimes of electron-hole pairs photogenerated in colloidal hematite solutions [48].

If the hole diffusion lengths reported for hematite are relevant to the ferric oxide OMEs, a significant fraction of holes would not reach the aqueous interface to form oxygenoxygen bonds. This likely explains the low photocurrent efficiency observed. In future work could be rigorously tested with the methodology developed here but with smaller beads as templates. We note that $20 \mathrm{~nm}$ beads are commercially available and are predicted to yield ferric oxide OMEs with solid features only $2-4 \mathrm{~nm}$ in radius. This is very close to the hole diffusion length estimated for hematite and would be expected to increase the solar conversion efficiency for water splitting.

\section{Conclusion}

The electrodeposition of ferric oxides into colloidal crystal templates was successfully achieved. The resultant ordered macroporous electrodes were about 2 microns thick with the inverse structure of the colloidal templates. Spectroscopic characterization did not match a known phase of ferric oxide but suggested a mixture of goethite and hematite. The photocurrent action spectra in the visible region revealed a more favorable band gap $(1.85 \mathrm{eV})$ than known polymorphs of ferric oxide. However, the photocurrents were disappointingly small, even with a substantial positive applied potential. Holes that were photogenerated in the centers of octahedral and tetrahedral sites within these ordered macroscopic electrodes must traverse hundreds of nanometers to reach the aqueous interface. Charge recombination likely limits the hole diffusion length and therefore represents a significant loss mechanism in the solar energy conversion efficiency. While the efficiency toward practical water splitting was disappointing for these specific ferric oxide mesoporous electrodes, the ability to synthesize finely tuned architectures on the nanometer length scale provides exciting new opportunities for future energy applications.

\section{Acknowledgments}

This work was supported by the National Science Foundation and the Johns Hopkins MRSEC.

\section{References}

[1] A. J. Bard and M. A. Fox, "Artificial photosynthesis: solar splitting of water to hydrogen and oxygen," Accounts of Chemical Research, vol. 28, no. 3, pp. 141-145, 1995.

[2] A. Fujishima and K. Honda, "Electrochemical photolysis of water at a semiconductor electrode," Nature, vol. 238, no. 5358, pp. 37-38, 1972.

[3] M. A. Butler, "Photoelectrolysis and physical properties of the semiconducting electrode $\mathrm{WO}_{2}$," Journal of Applied Physics, vol. 48, no. 5, pp. 1914-1920, 1977.

[4] G. Hodes, D. Cahen, and J. Manassen, "Tungsten trioxide as a photoanode for a photoelectrochemical cell (PEC)," Nature, vol. 260 , no. 5549 , pp. 312-313, 1976.

[5] M. S. Wrighton, A. B. Ellis, P. T. Wolczanski, D. L. Morse, H. B. Abrahamson, and D. S. Ginley, "Strontium titanate photoelectrodes. Efficient photoassisted electrolysis of water at zero applied potential," Journal of the American Chemical Society, vol. 98, no. 10, pp. 2774-2779, 1976.

[6] M. Anderman and J. H. Kennedy, "Semiconductor electrodes: IRON OXIDE $\left(\mathrm{Fe}_{2} \mathrm{O}_{3}\right)$," in Studies in Physical and Theoretical Chemistry, H. O. Finklea, Ed., vol. 55, Elsevier, Amsterdam, The Netherlands, 1988.

[7] NREL Reference Solar Spectral Irradiance: Air Mass 1.5, http://rredc.nrel.gov/solar/spectra/am1.5/.

[8] Y. V. Pleskov and Y. Y. Gurevich, Semiconductor Photoelectrochemistry, Consultants Bureau, New York, NY, USA, 1986. 
[9] M. P. Dare-Edwards, J. B. Goodenough, A. Hamnett, and P. R. Trevellick, "Electrochemistry and photoelectrochemistry of iron(III) oxide," Journal of the Chemical Society, Faraday Transactions 1, vol. 79, no. 9, pp. 2027-2041, 1983.

[10] K. L. Hardee and A. J. Bard, "Semiconductor electrodes. V. The application of chemically vapor deposited iron oxide films to photosensitized electrolysis," Journal of the Electrochemical Society, vol. 123, no. 7, pp. 1024-1026, 1976.

[11] K. L. Hardee and A. J. Bard, "Semiconductor electrodes. $\mathrm{X}$. Photoelectrochemical behavior Of several polycrystalline metal oxide electrodes in aqueous solutions," Journal of the Electrochemical Society, vol. 124, no. 2, pp. 215-224, 1977.

[12] K. Itoh and J. O. Bockris, "Thin film photoelectrochemistry: iron oxide," Journal of the Electrochemical Society, vol. 131, no. 6, pp. 1266-1271, 1984.

[13] K. Itoh and J. O. Bockris, "Stacked thin-film photoelectrode using iron oxide," Journal of Applied Physics, vol. 56, no. 3, pp. 874-876, 1984.

[14] J. H. Kennedy and M. Anderman, "Photoelectrolysis of water at $\alpha-\mathrm{Fe}_{2} \mathrm{O}_{3}$ electrodes in acidic solution," Journal of the Electrochemical Society, vol. 130, no. 4, pp. 848-852, 1983.

[15] J. H. Kennedy and K. W. Frese Jr., "Photooxidation of water at $\alpha-\mathrm{Fe}_{2} \mathrm{O}_{3}$ electrodes," Journal of the Electrochemical Society, vol. 125 , no. 5, pp. 709-714, 1978.

[16] J. H. Kennedy and K. W. Frese Jr., "Flatband potentials and donor densities of polycrystalline $\alpha$ - $\mathrm{Fe}_{2} \mathrm{O}_{3}$ determined from mott-schottky plots," Journal of the Electrochemical Society, vol. 125 , no. 5, pp. 723-726, 1978.

[17] J. H. Kennedy, R. Shinar, and J. Ziegler, "Alpha- $\mathrm{Fe}_{2} \mathrm{O}_{3}$ photoanodes doped with silicon," Journal of The Electrochemical Society, vol. 127, no. 10, pp. 2307-2309, 1980.

[18] M. M. Khader, G. H. Vurens, I.-K. Kim, M. Salmeron, and G. A. Somorjai, "Photoassisted catalytic dissociation of $\mathrm{H}_{2} \mathrm{O}$ to produce hydrogen on partially reduced $\alpha-\mathrm{Fe}_{2} \mathrm{O}_{3}$," Journal of the American Chemical Society, vol. 109, no. 12, pp.3581-3585, 1987.

[19] A. F. Sammells and P. G. P. Ang, "Enhanced photoeffects at n-type iron oxide electrodes by electrocatalysis and peroxide effects," Journal of the Electrochemical Society, vol. 126, no. 10, pp. 1831-1832, 1979.

[20] J. E. Turner, M. Hendewerk, J. Parmeter, D. Neiman, and G. A. Somorjai, "Characterization of doped iron oxide electrodes for the photodissociation of water," Journal of the Electrochemical Society, vol. 131, no. 8, pp. 1777-1783, 1984.

[21] S. M. Wilhelm, K. S. Yun, L. W. Ballenger, and N. Hackerman, "Semiconductor properties of iron oxide electrodes," Journal of the Electrochemical Society, vol. 126, no. 3, pp. 419-423, 1979.

[22] U. Björksten, J. Moser, and M. Grätzel, "Photoelectrochemical studies onnanocrystalline hematite films," Chemistry of Materials, vol. 6, no. 6, pp. 858-863, 1994.

[23] I. Cesar, A. Kay, J. A.G. Martinez, and M. Grätzel, “Translucent thin film $\mathrm{Fe}_{2} \mathrm{O}_{3}$ photoanodes for efficient water splitting by sunlight: nanostructure-directing effect of Si-doping," Journal of the American Chemical Society, vol. 128, no. 14, pp. 45824583, 2006.

[24] K. Ehrensberger, A. Frei, P. Kuhn, H. R. Oswald, and P. Hug, "Comparative experimental investigations of the watersplitting reaction with iron oxide $\mathrm{Fe}_{1-y} \mathrm{O}$ and iron manganese oxides $\left(\mathrm{Fe}_{1-\mathrm{x}} \mathrm{Mn}_{\mathrm{x}}\right)_{1-\mathrm{y}} \mathrm{O}$," Solid State Ionics, vol. 78, no. 1-2, pp. 151-160, 1995.

[25] M. A. Gondal, A. Hameed, Z. H. Yamani, and A. Suwaiyan, "Laser induced photo-catalytic oxidation/splitting of water over $\alpha-\mathrm{Fe}_{2} \mathrm{O}_{3}, \mathrm{WO}_{3}, \mathrm{TiO}_{2}$ and $\mathrm{NiO}$ catalysts: activity comparison," Chemical Physics Letters, vol. 385, no. 1-2, pp. 111-115, 2004.

[26] S. U. M. Khan and J. Akikusa, "Photoelectrochemical splitting ofwater at nanocrystalline n- $\mathrm{Fe}_{2} \mathrm{O}_{3}$ thin-film electrodes," Journal of Physical Chemistry B, vol. 103, no. 34, pp. 71847189, 1999.

[27] W. B. Ingler Jr., J. P. Baltrus, and S. U. M. Khan, "Photoresponse of p-Type zinc-doped iron(III) oxide thin films," Journal of the American Chemical Society, vol. 126, no. 33, pp. 10238-10239, 2004.

[28] D. K. Zhong, J. Sun, H. Inumaru, and D. R. Gamelin, "Solar water oxidation by composite catalyst $/ \alpha-\mathrm{Fe}_{2} \mathrm{O}_{3}$ photoanodes," Journal of the American Chemical Society, vol. 131, no. 17, pp. 6086-6087, 2009.

[29] J. S. Jang, J. Lee, H. Ye, F.-R. F. Fan, and A. J. Bard, "Rapid screening of effective dopants for $\mathrm{Fe}_{2} \mathrm{O}_{3}$ photocatalysts with Scanning electrochemical microscopy and investigation of their photoelectrochemical properties," Journal of Physical Chemistry C, vol. 113, no. 16, pp. 6719-6724, 2009.

[30] T. Lindgren, H. Wang, N. Beermann, L. Vayssieres, A. Hagfeldt, and S.-E. Lindquist, "Aqueous photoelectrochemistry of hematite nanorod array," Solar Energy Materials and Solar Cells, vol. 71, no. 2, pp. 231-243, 2002.

[31] S. A. Majumder and S. U. M. Khan, "Photoelectrolysis of water at bare and electrocatalyst covered thin film iron oxide electrode," International Journal of Hydrogen Energy, vol. 19, no. 11, pp. 881-887, 1994.

[32] C. J. Sartoretti, B. D. Alexander, R. Solarska, I. A. Rutkowska, J. Augustynski, and R. Cerny, "Photoelectrochemical oxidation of water at transparent ferric oxide film electrodes," Journal of Physical Chemistry B, vol. 109, no. 28, pp. 13685-13692, 2005.

[33] C. J. Sartoretti, M. Ulmann, B. D. Alexander, J. Augustynski, and A. Weidenkaff, "Photoelectrochemical oxidation of water at transparent ferric oxide film electrodes," Chemical Physics Letters, vol. 376, no. 1-2, pp. 194-200, 2003.

[34] Z. Zhou, L. Jiang, and J. Zhang, "Photoelectric characterization of a thin film of iron oxide $\alpha-\mathrm{Fe}_{2} \mathrm{O}_{3}$," Gazzetta Chimica Italiana, vol. 123, no. 8, pp. 471-473, 1993.

[35] K. E. Davis, W. B. Russel, and W. J. Glantschnig, "Disorder-toorder transition in settling suspensions of colloidal silica: Xray measurements," Science, vol. 245, no. 4917, pp. 507-510, 1989.

[36] O. D. Velev, T. A. Jede, R. F. Lobo, and A. M. Lenhoff, "Porous silica via colloidal crystallization,” Nature, vol. 389, no. 6650, pp. 447-448, 1997.

[37] Y. Hao, F. Q. Zhu, C. L. Chien, and P. C. Searson, "Fabrication and magnetic properties of ordered macroporous nickel structures," Journal of the Electrochemical Society, vol. 154, no. 2, pp. D65-D69, 2007.

[38] D. Hung, Z. Liu, N. Shah, Y. Hao, and P. C. Searson, "Finite size effects in ordered macroporous electrodes fabricated by electrodeposition into colloidal crystal templates," Journal of Physical Chemistry C, vol. 111, no. 8, pp. 3308-3313, 2007.

[39] S. Peulon, H. Antony, L. Legrand, and A. Chausse, "Thin layers of iron corrosion products electrochemically deposited on inert substrates: synthesis and behaviour," Electrochimica Acta, vol. 49, no. 17-18, pp. 2891-2899, 2004.

[40] R. M. Cornell and U. Schwertmann, The Iron Oxides: Structure, Properties, Reactions, Occurrences, and Uses, John Wiley \& Sons, Weinheim, Germany, 2nd edition, 2003.

[41] R. M. Silverstein, G. C. Bassler, and T. C. Morrill, Spectrometric Identification of Organic Compounds, John Wiley \& Sons, New York, NY, USA, 4th edition, 1981. 
[42] U. Schwertmann and R. M. Cornell, Iron Oxides in the Laboratory: Preparation and Characterization, John Wiley \& Sons, Weinheim, Germany, 1991.

[43] E. J. Johnson, "Absorption near the fundamental edge," in Semiconductors and Semimetals, R. K. Willardson and A. C. Beer, Eds., vol. 3, Academic Press, New York, NY, USA, 1967.

[44] J. K. Leland and A. J. Bard, "Photochemistry of colloidal semiconducting iron oxide polymorphs," Journal of Physical Chemistry, vol. 91, no. 19, pp. 5076-5083, 1987.

[45] S. R. Morrison and T. Freund, "Chemical role of holes and electrons in ZnO photocatalysis," The Journal of Chemical Physics, vol. 47, no. 4, pp. 1543-1551, 1967.

[46] S. R. Morrison and T. Freund, "Chemical reactions of electrons and holes at the $\mathrm{ZnO} /$ electrolyte-solution interface," Electrochimica Acta, vol. 13, no. 6, pp. 1343-1349, 1968.

[47] T. Lindgren, L. Vayssieres, H. Wang, and S.-E. Lindquist, "Photo-oxidation of water at hematite electrodes," in Chemical Physics of Nanostructured Semiconductors, A. I. Kokorin and D. W. Bahnemann, Eds., VSP, Utrecht, The Netherlands, 2003.

[48] N. J. Cherepy, D. B. Liston, J. A. Lovejoy, H. Deng, and J. Z. Zhang, "Ultrafast studies of photoexcited electron dynamics in $\gamma$ - and $\alpha-\mathrm{Fe}_{2} \mathrm{O}_{3}$ semiconductor nanoparticles," Journal of Physical Chemistry B, vol. 102, no. 5, pp. 770-776, 1998. 

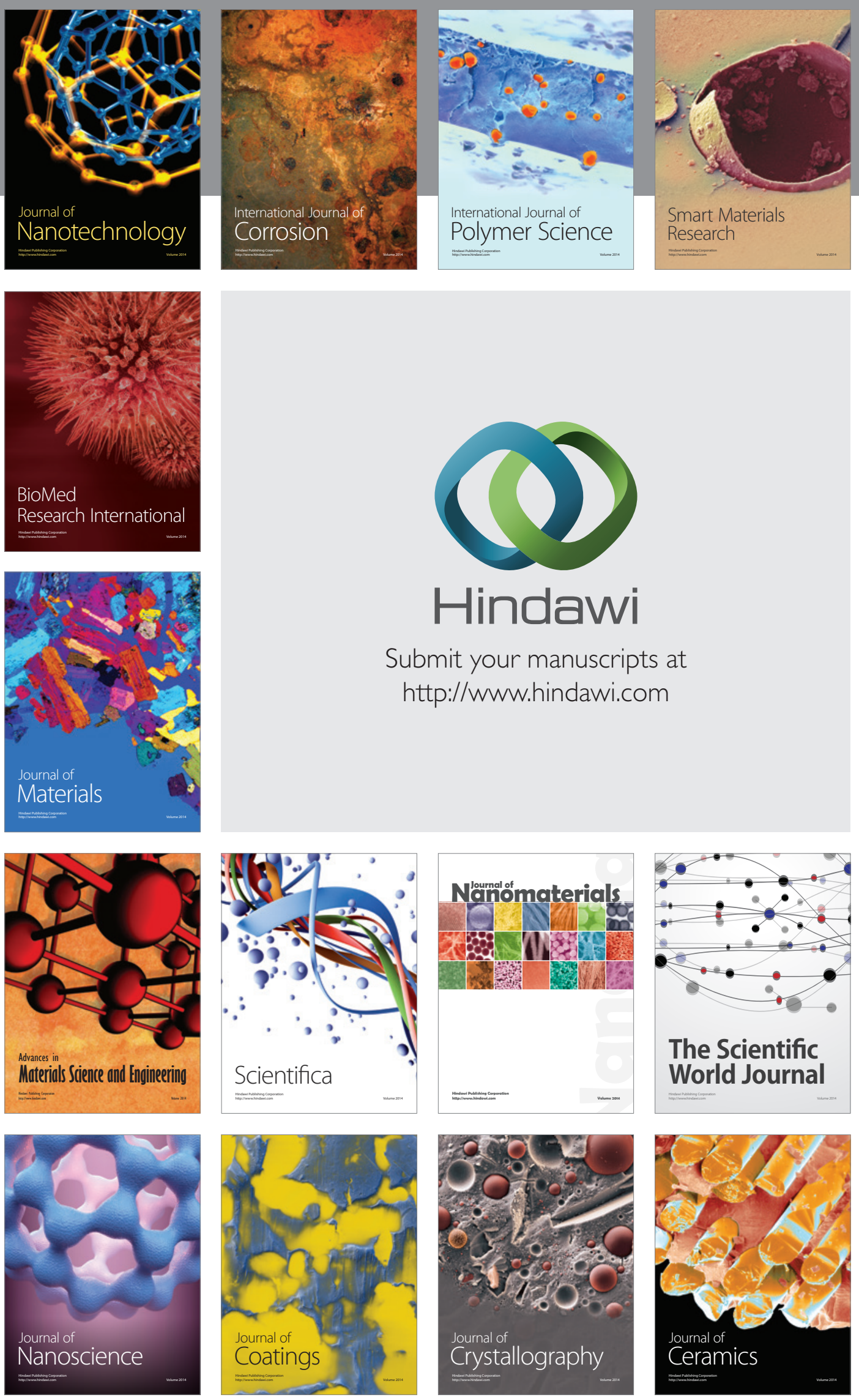

The Scientific World Journal

Submit your manuscripts at

http://www.hindawi.com

\section{World Journal}

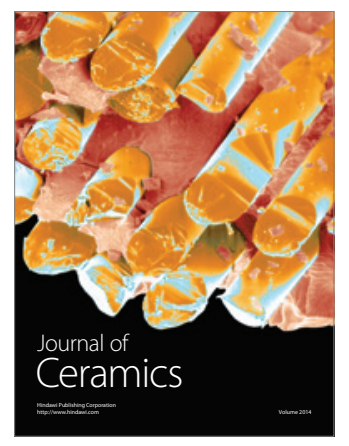

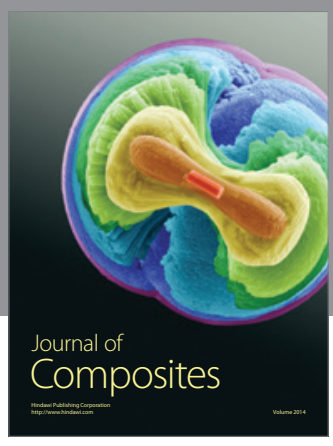
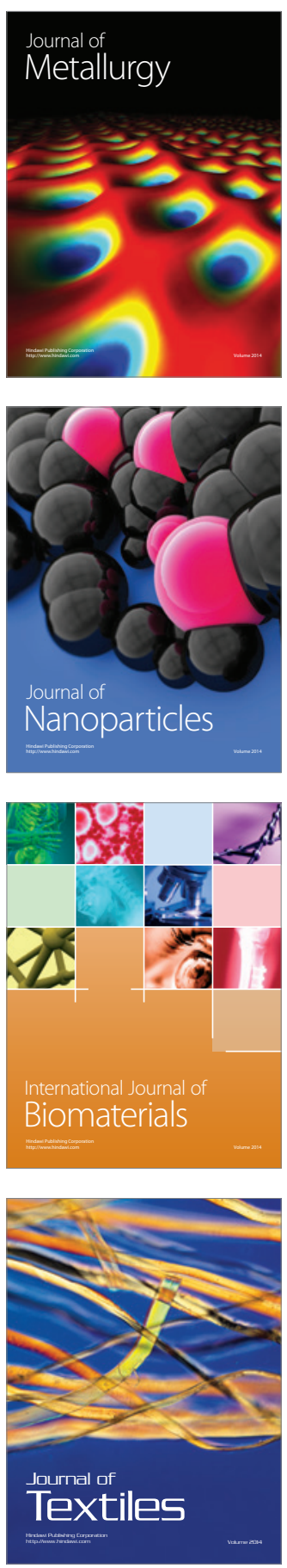